\title{
On the Damping Behaviour of NiTi Shape Memory Alloy
}

\author{
Y. Liu and J. van Humbeeck \\ Department MTM, Katholieke Universiteit Leuven, de Croylaan 2, 3001 Heverlee, Belgium
}

\begin{abstract}
Shape memory alloys exhibit a high damping capacity in the martensite state. Results obtained from both DMA and cyclic tests under tension-compression load show that the martensite damping capacity in NiTi SMAs is a function of both strain amplitude and annealing temperature. Internal friction due to movements of martensite twin boundaries within both elastic (accommodation) and inelastic (reorientation) ranges as a function of strain amplitude seems to be consistent. A critical annealing temperature exists for deformed NiTi SMAs in order to obtain a high martensite damping capacity. Under tension-compression cyclic loading, the martensite damping decreases as the number of cycles increases, and it tends to stabilize with further cycling.
\end{abstract}

\section{INTRODUCTION}

Shape memory alloys possess a high damping capacity [1-12] both in the austenite state due to stress induced martensitic transformation and in the martensite state due to stress-induced martensite variants reorientation. This high damping capacity sheds new light on the applications of SMAs. Civil engineering applications of SMAs are attracting more attention recently, especially on protections of architectures from vibration damages [13-19]. Both $\mathrm{Cu}$-base and NiTi-base shape memory alloys have been studied by earlier researchers. However, so far, most of the attention has been paid only to the materials under pseudoelastic loading, and the damping capacity of martensite has not been systematically studied. In the present research, the damping capacity of martensite in NiTi SMAs has been studied as a function of annealing condition, strain amplitude $\left(10^{-5}-10^{-2}\right)$, and strain rate: Results obtained from a NiTi rolled sheet and a NiTi drawn bar are presented. A DMA (Dynamical Mechanical Analyzer) and an Instron tester under tension-compression cyclic loading have been used to determine the damping of the materials.

\section{EXPERIMENTAL DETAILS}

Internal friction - A DuPont 983 DMA at a resonant frequency mode has been used to measure the internal friction of a near-equiatomic NiTi rolled sheet as a function of temperature. Samples with a size of 36 $\times 5 \times 1.4 \mathrm{~mm}^{3}$ were spark cut along the rolling direction and then annealed at temperatures between 300 and $800^{\circ} \mathrm{C}$ for $30 \mathrm{~min}$ in air followed by a water-quench (WQ) to room temperature (RT). During measurements, the samples were first quickly heated to $150^{\circ} \mathrm{C}$, which is well above the $A_{\mathrm{f}}$ temperature, and then cooled to $-100^{\circ} \mathrm{C}$ and again heated to $150^{\circ} \mathrm{C}$ at a rate of $5 \mathrm{~K} / \mathrm{min}$.

Cyclic tests - The tension-compression (sinusoidal load) cyclic tests were performed on an Instron machine at room temperature. A binary NiTi drawn bar ( $\phi 6.7)$, annealed at temperatures between 450 and $800^{\circ} \mathrm{C}$ for $30 \mathrm{~min}$ followed by WQ to RT, was tested with a length of $27 \mathrm{~mm}$ between the clamps. An extensometer with $12.5 \mathrm{~mm}$ gauge length was used to determine the strain. Three maximum setting strains were chosen, i.e. $1 \%, 2 \%$ and $4 \%$. Up to 10 or 50 cycles for each test were performed. In some cases, in order to obtain the same strain rate, the testing frequency was adjusted for different setting strains. Strain rates from $1.6 \times 10^{-3}$ to $8 \times 10^{-2} \mathrm{~s}^{-1}$ which corresponds with $0.01 \mathrm{~Hz}$ to $0.5 \mathrm{~Hz}$ for a maximum strain of $4 \%$ were applied. Before testing, all the specimens have been quenched into liquid nitrogen, which ensures that the martensitic transformation is complete after quenching and the martensite phase is stable at RT. $M_{\mathrm{s}}, M_{\mathrm{f}}, A_{\mathrm{s}}$, and $A_{\mathrm{f}}$ temperatures have been determined by DSC. 


\section{RESULTS AND DISCUSSION}

Internal friction - Damping of a NiTi sheet at low strain amplitude $\left(<10^{-2}\right)$ as a function of temperature is obtained with DMA (Fig. 1). Two internal friction peaks (Pc1, Pc2) related to the forward phase transformations appear during cooling. During heating, a reverse transformation occurs which corresponds to a maximum damping (Ph1) and a sharp increase in the modulus [11,12]. Below the $A_{\mathrm{s}}$ temperatures, the internal friction, however, remains nearly constant in a rather wide temperature range before the reverse transformation takes place. The magnitude of this damping increases with increasing vibration strain amplitude as shown in Fig. 1b.

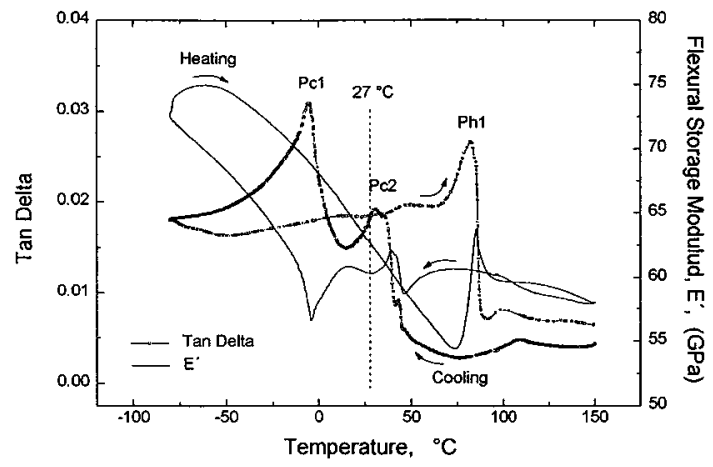

a)

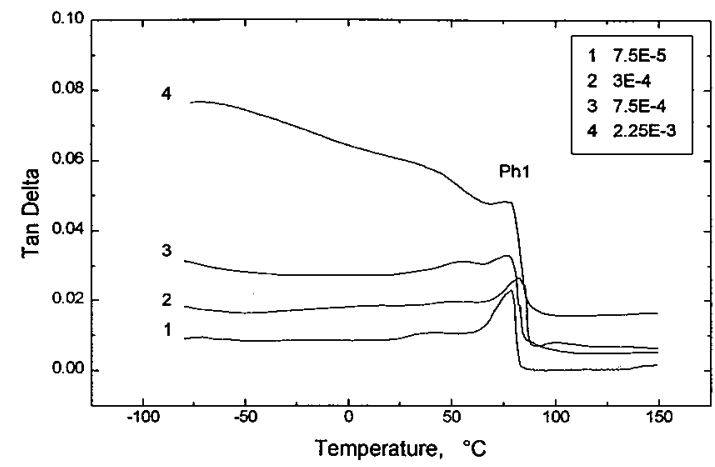

b)

Figure 1: Damping of a NiTi sheet $\left(600^{\circ} \mathrm{C}\right.$ WQ) during (a) cooling and heating (strain amplitude $\left.=3 \times 10^{-4}\right)$, and (b) heating as a function of strain amplitude.

Cyclic tests - Specimens of a NiTi bar with several annealing conditions have been cycled between $\pm \mathbf{1 \%}$, $\pm 2 \%$ and $\pm 4 \%$ strains. Figure 2 shows stress-strain curves of specimens with two different annealing treatments. Figure 3 shows that during cycling, the maximum tension and compression stresses shifted to higher levels after each cycle. However, after about 10 cycles the stress-increase became insignificant and the stress-strain loops are nearly stabilized. In Fig. 3, the $\sigma_{1}$ and $\sigma_{i}\left(\Delta \sigma=\sigma_{i}-\sigma_{1}\right)$ denote the maximum stresses of the 1st and the $i$ th cycles, respectively. Variation of $\Delta \sigma$ as a function of number of cycles shows that, during cycling, the stress-increase under compression is slightly higher than that in tension at strains less than $2 \%$, however, it is much higher at $4 \%$ strain. The changing rate of the stress, $d \sigma / \mathrm{dn}$, gradually reaches zero as the loop number increases.

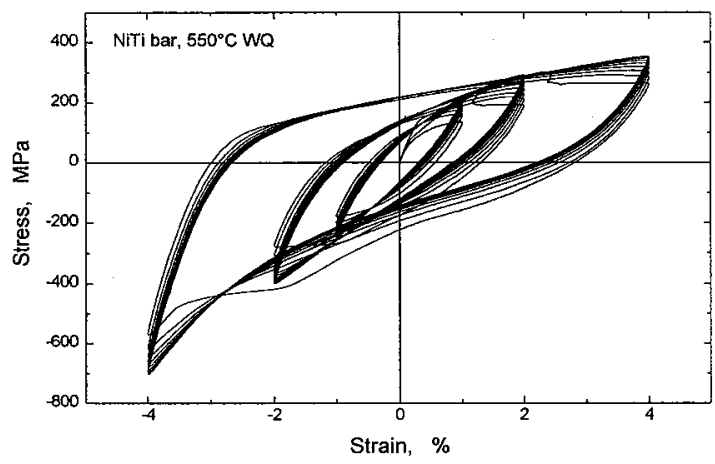

a)

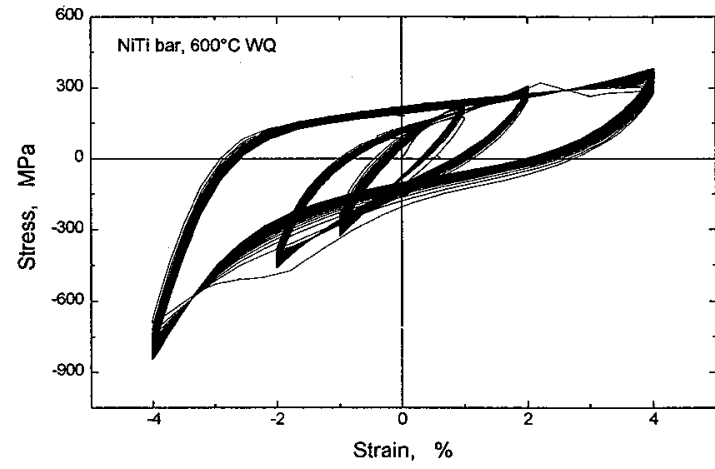

b)

Figure 2: Stress-strain curves of NiTi bar under tension-compression at strain rate of $0.016 \mathrm{~s}^{-1}$ for two annealing conditions. 

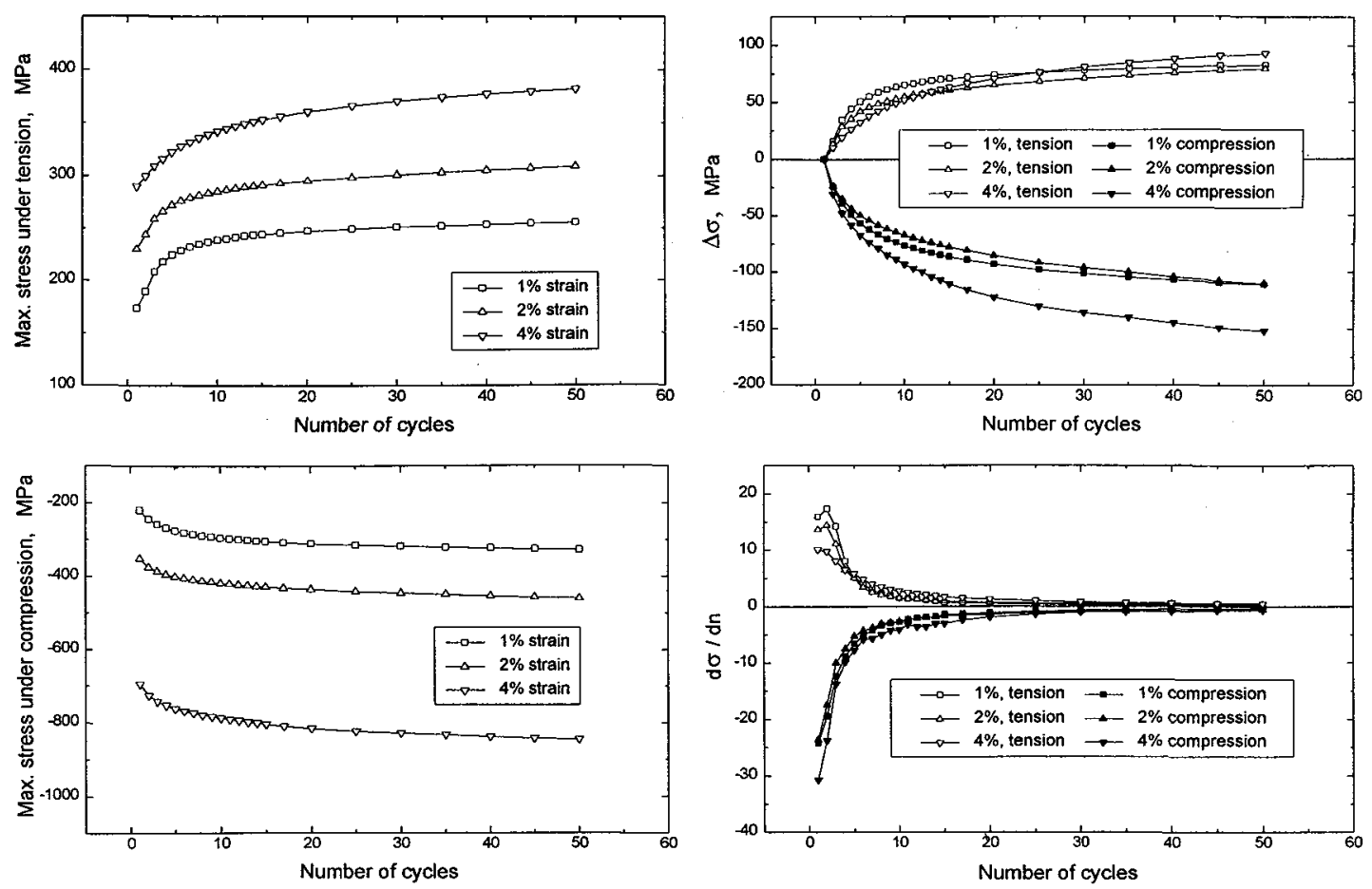

Figure 3: Maximum tension and compression stresses and their changing rates as a function of number of cycles. $\sigma_{1}$ and $\sigma_{i}$ are the maximum stresses of the 1 st and the $i$ th cycles, respectively $\left(\Delta \sigma=\sigma_{i}-\sigma_{i}\right)$. Data were taken from Fig. $2 \mathrm{~b}$.

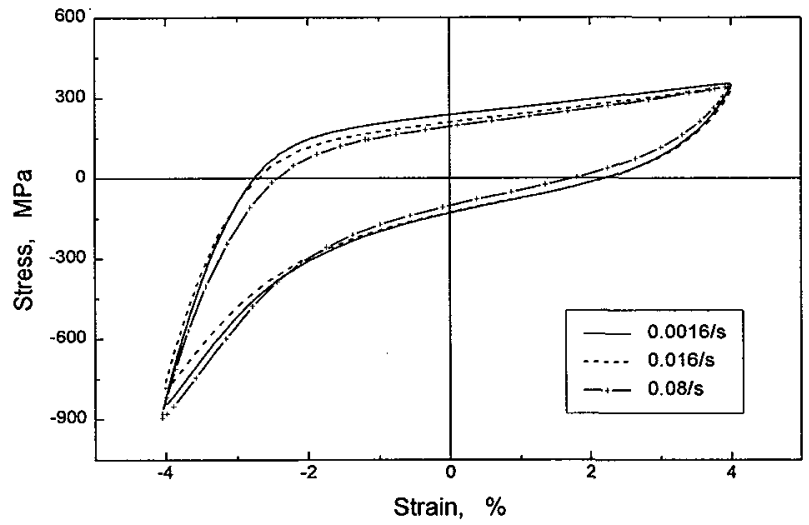

Figure 4: Effect of strain rate on the stress-strain loop (10th loop) of NiTi bar $\left(600^{\circ} \mathrm{C} \mathrm{WQ}\right)$ under tension-compression cyclic load.

The stress-strain loops of the 10th cycle of each test as a function of strain rate are plotted in Fig. 4 . Results show that the strain rate has slight influence on the shape of stress-strain loops. The area inside the stress-strain loop represents the energy loss $(\Delta W)$ during one cycle of loading, while the total area between zero-stress axis and tension and compression curves represents the total work (W) done on the specimen. The internal friction $(\Delta \mathrm{W} / 2 \pi \mathrm{W})$ of the specimen can thus be obtained. As shown in Fig. 5 , the martensite damping capacity decreases with increasing number of testing cycles and increases with increasing deformation amplitude. However, the decreasing tendency slows down when the test exceeds about 10 cycles. The temperature of the specimen is also a function of both the strain rate and the strain 
amplitude. For lower strain rate or lower strain amplitude, the temperature of the specimen tends to stabilize with further cycling.
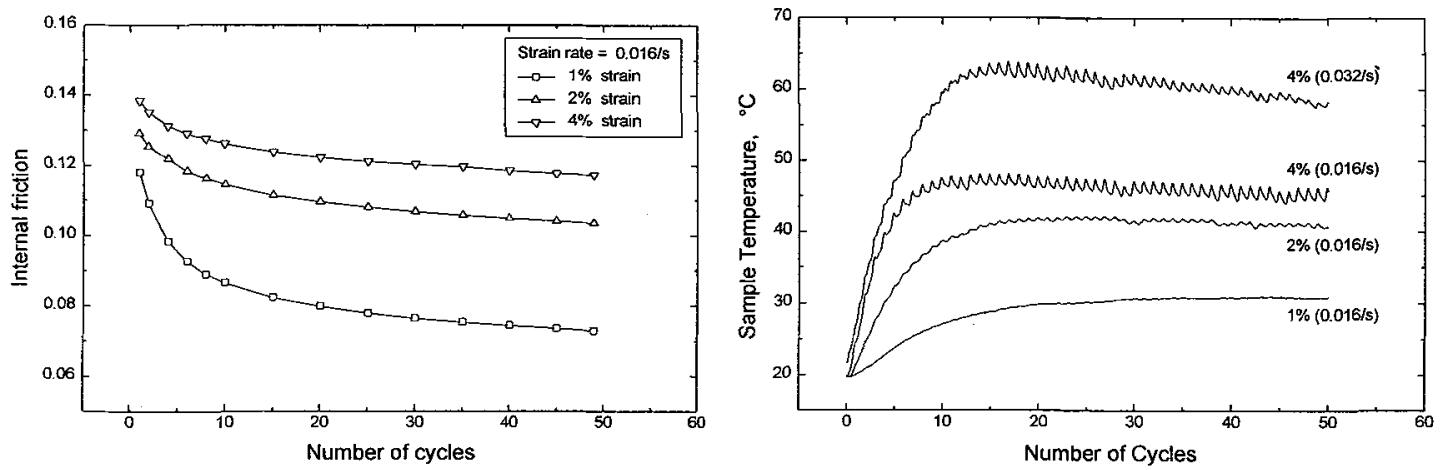

Figure 5: Martensite damping (data were taken from Fig. 2b) and sample temperature of a NiTi bar as a function of cycling loops and strain amplitudes.

The internal friction of martensite of both the NiTi sheet (lower strain amplitude) and the NiTi bar (higher strain amplitude) as a function of annealing temperature is plotted in Fig. 6. For NiTi sheet at low stain amplitude $\left(3 \times 10^{-5}\right)$, the martensite damping increases systematically with increasing annealing temperature below $550^{\circ} \mathrm{C}$ and it decreases when the sample is annealed above $550^{\circ} \mathrm{C}$ [11]. Each data point shown in Fig. $6 \mathrm{a}$ is an average value of about 3 measurements by using a new specimen each time. For the NiTi bar, at higher strain amplitude (above $1 \times 10^{-2}$ ), the martensite damping increases with increasing annealing temperature and saturates when the temperature is above $550^{\circ} \mathrm{C}$.
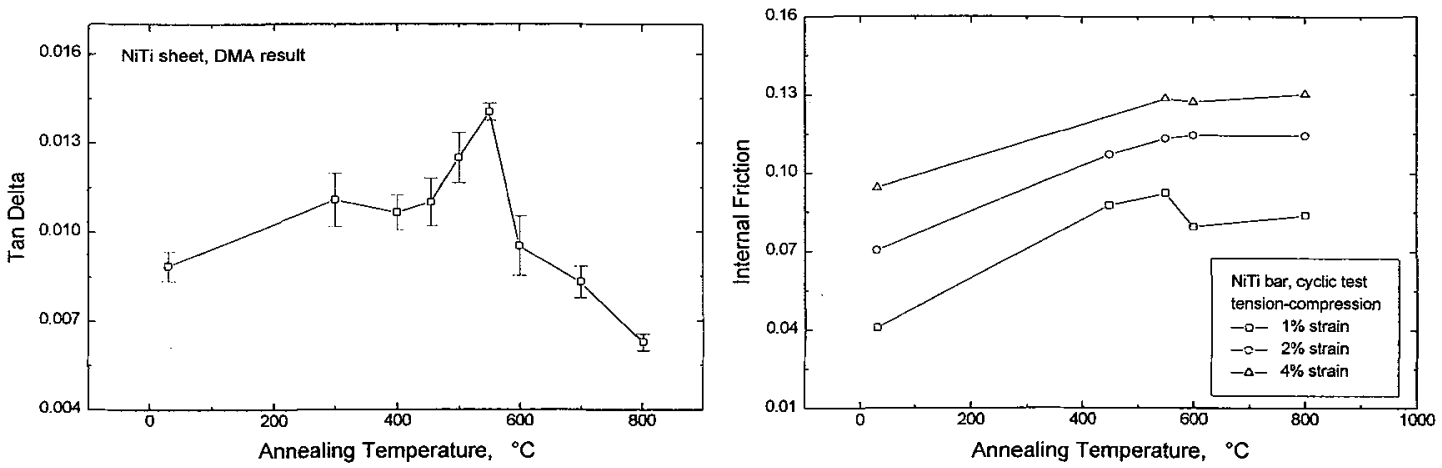

Figure 6: Martensite damping of a deformed NiTi sheet (strain amplitude $=3 \times 10^{-5}$ ) and a NiTi bar (10th cycle) as a function of annealing temperature.

Figure 7 schematically shows a stress-strain curve of a SMA under tension. At lower strain, three regions can be defined [20]. Range I is related to the elastic deformation of SMA which has been proposed to be due to the accommodation/movements/reorientation of martensite twin boundaries. Range II is related to the inelastic (stress plateau) movements of martensite twin boundaries and it has been proposed to be due to the martensite reorientation/detwinning process. Range III starts from the end of the plateau and is related to the elastic deformation of fully reoriented/detwinned martensite. With further increasing the load, plastic deformation of martensite will occur. Since it may be confusing of using several words to describe one process, for the convenience of discussion, we tentatively propose to use the term twin accommodation to describe the process of the twin boundary movements within the elastic range, 
and the term martensite reorientation to describe the process of the twin "boundary movements within the inelastic range (stress plateau) where various variants of martensite finally reorient to a single orientation.

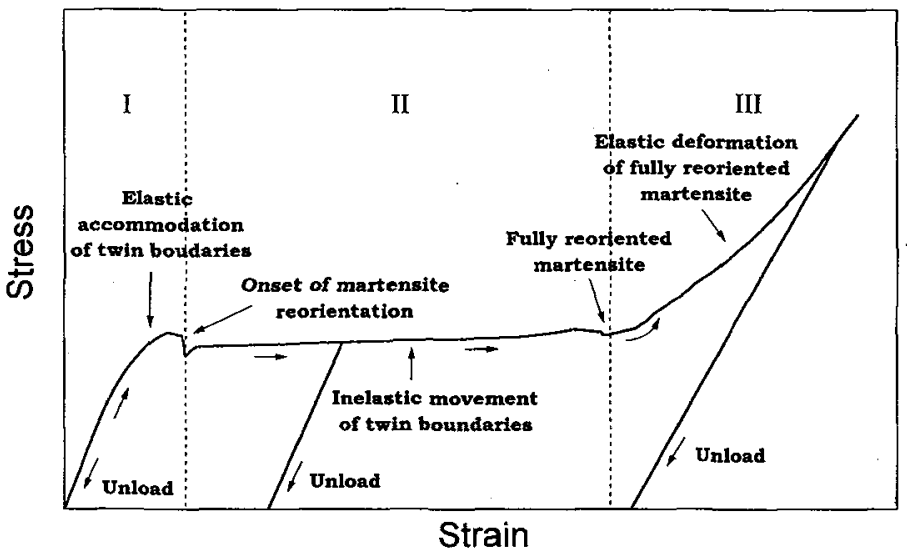

Figure 7: Schematic diagram showing the stress-strain curve of shape memory alloy at lower strain range under tension. Three regions can be classified: region $I$ is the elastic deformation of SMA which is related to the elastic accommodation of twin boundaries; region II is related to the martensite reorientation, which is an inelastic process, and region III is related to the elastic deformation of fully reoriented martensite.

Both the twin accommodation and the martensite reorientation can give rise to an internal friction The internal friction caused by twin accommodations can occur at a strain amplitude as low as $7.5 \times 10^{-5}$ as shown in Fig. 1b. While the internal friction due to martensite reorientation takes place in the strain range above about $1 \times 10^{-2}$ where a stress plateau occurs. In this range, the deformation of the material is partially irreversible, i.e. the deformed specimen can not recover to its original shape without variation of external parameters. This suggests that the martensite reorientation results in a metastable state of the microstructure, which is achieved by overcoming an energy barrier. This is indicated by a stress drop at the onset of the martensite reorientation (see Fig. 7). Plotting the internal friction data of both the NiTi sheet and the NiTi bar in Fig. 8 as a function of strain amplitude, it clearly shows that although the testing methods and the materials were different, the overall tendency of the internal friction is somehow similar, and the internal friction magnitude from both types of tests falls into a comparable range. Two different processes result in a somehow consistent internal friction value. This can be understood by the fact that both processes are related to the same type of microstructural defects, i.e. martensite twin boundaries. At lower strain amplitude $\left(\sim 10^{-4}\right)$, about $6 \%$ of the mechanical energy can be consumed during one cycle of loading, while at higher strains $\left(\sim 4 \times 10^{-2}\right)$, nearly $80 \%$ of the mechanical energy can be consumed.

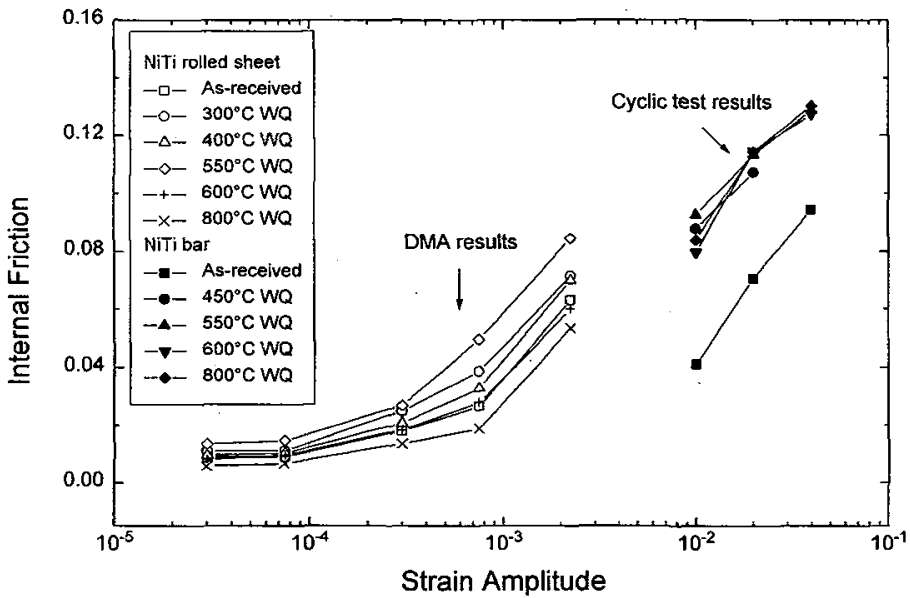

Figure 8: Internal friction of both $\mathrm{NiTi}$ sheet and NiTi bar as a function of strain amplitudes for several annealing treatments. The cyclic tests were conducted at $\mathrm{RT}$, while the DMA data were taken from testing results at $27^{\circ} \mathrm{C}$ (see Fig. 1). 


\section{CONCLUSIONS}

Based on the present results, the following major conclusions can be drawn:

1. The martensite damping capacity of deformed NiTi SMAs is a function of annealing condition.

2. Under tension-compression cyclic loading, martensite damping decreases with increasing number of cycles, and it tends to stabilize with further cycling.

3. The martensite damping as a function of strain amplitude seems to be consistent between elastic and inelastic deformation region.

4. Under cyclic loading, the maximum stresses of both tension and compression increase with increasing testing cycles. However, the increasing rate slows down with further cycling.

5. The temperature of the specimen increases with increasing both the strain rate and the strain amplitude. At lower strain rate, it tends to stabilize when the test exceeds a certain number of cycles.

\section{Acknowledgments}

The authors are grateful to Prof. L. Delaey and Dr. R. Stalmans for helpful discussions. J. Van Humbeeck acknowledges the NFWO (National Foundation for Scientific Research, Belgium) for a support by contract No. 20093.93. Part of this work has been financed by BRITE project, MANSIDE contract No. BRPR-CT95-0031.

\section{References}

[1] Hasiguti R. R. and Iwasaki K., J. Appl. Phys. 39 (1968) 2182-2186.

[2] De Jonghe W., De Batist R., Delaey L. and De Bonte M., Shape Memory Effects in Alloys (Plenum Press, New York, 1975, ed. J. Perkins), pp. 451-466.

[3] Mercier O., Melton K. N. and De Preville Y., Acta Metall. 27 (1979) 1467-1475.

[4] Van Humbeeck J., "Internal Friction in Shape Memory Alloys", Proc. ICIFUAS-90, T. S. Ke Eds. (Oxford, 1990) pp. 337-344.

[5] Huang Y. T., Yang G. P. and He P., Scripta Met. 19 (1985) 1033-1038; 1039-1044.

[6] Wu S. K., Lin H. C. and Chou T. S., Acta Met. 38 (1990) 95-102.

[7] Iwasaki K. and Hasiguti R., Trans. JIM 28 (1987) 363-367.

[8] De Jonghe W., Delaey L., De Batist R, and Van Humbeeck J., Met. Sci., 11 (1977) 523-530.

[9] Lin H. C., Wu S. K. and Yeh M. T., Metall. Trans. 24A (1993) 2189-2194.

[10] Morin M., Guenin G. and Gobin P. F., J. de Phys. 43 (1982) C4-685-689.

[11] Liu, Y., Van Humbeeck J., Stalmans R. and Delaey L., J. of Alloys and Compounds, in press.

[12] Liu, Y., Van Humbeeck J., Stalmans R. and Delaey L., "Damping related properties of NiTi shape memory alloy", International Conference on Displacive Phase Transformations and Their Applications in Materials Engineering, Urbana, Illinois, USA, May 8-9, 1996, to be published.

[13] Graesser E. J. and Cozzarelli F. A., J. of Eng. Mechanics 117 (1991) 2590-2608.

[14] Wittig P. R. and Cozzarelli F. A., Proc. of Damping'93, Feb. 1993, San Francisco, ECC-1-19.

[15] Graesser E. J. and Cozzarelli F. A., Proc. of Damping'93, Feb. 1993, San Francisco, ECB-1-28.

[16] Graesser E. J. and Cozzarelli F. A., J. Intelligent Mart. Syst. and Struct. 5 (1994) 78-89.

[17] Hodgson D. E. and Krumme R. C., "Damping in Structural Applications", Proc. I st Internat. Conf. on Shape Memory and Superelastic Techn., California 7-10 March 1994, A.R. Pelton, et al. Eds. pp. 371-376.

[18] Wittig P. R. and Cozzarelli F. A., Technical Report NCEER-92-0013, National Center for Earthquake Engineering Research, State Univ. of New York at Buffalo, USA, 1992.

[19] Whittaker A. S., Krumme R. and Hayes R. Jr., Technical Report TR 95/22, US Army Construction Engineering Research Laboratories, 1995.

[20] Wayman C. M. and Duerig T. W., Engineering Aspects of Shape Memory Alloys (Butterworth-Heinemann, London, 1990) pp. 3-20. 